\title{
RECENSIÓN • LIBURU IRUZKINA \\ Sergio Pérez Castaños (2020). \\ Elecciones europeas de 2019: campaña electoral, voto y liderazgo. Barcelona: Tirant lo Blanch
}

\author{
Sandra García Santamaría \\ Universidad de Burgos
}

En esta obra colectiva coordinada por el profesor de la Universidad de Burgos, Sergio Pérez Castaños, se analizan, a través de diferentes técnicas y a lo largo de seis capítulos, los elementos más destacables del proceso electoral comunitario que tuvo lugar en mayo de 2019 y que resultó en la que será la composición del hemiciclo europeo hasta 2024. Del mismo modo se pone especial atención en la relevancia de la campaña electoral como elemento activador y se realiza una interesantísima radiografía de aquellas personas que representan o han representado a España dentro del hemiciclo europeo.

Y es que el estudio de las elecciones europeas resulta de especial relevancia en la medida en que se convierten en una caja de resonancia de la sociedad en que tienen lugar, adelantando las pulsiones y tensiones que esta enfrenta. Así, a lo largo de este trabajo, se presentan aquellos elementos y casuísticas a tener más en cuenta. A continuación, se exponen, sucintamente, los temas tratados en cada uno de los epígrafes.

En el primero de los capítulos, se repasa el contexto político y social en el que se encontraba - y aún se puede decir que se encuentra - la Unión Europea —UE, en adelante- de cara a afrontar diferentes cuestiones que se antojaban críticas para su futuro tales como la crisis de migrantes, el pulso de las fuerzas de derecha radical o el Brexit, entre otros (Pérez Castaños, 2020). A ellas se suma, en el primer trimestre del año, y de improviso, la gestión de la pandemia de COVID-19. A continuación se sientan las bases de los elementos que podrían influir en la imagen que la ciudadanía europea alberga con respecto al Parlamento, la UE y, sobre todo, su deriva en los próximos años. Los tintes euroescépticos y el desencanto social con respecto a las instituciones parece ser un comportamiento que también afecta a la esfera supranacional, y sin embargo, las elecciones de mayo de 2019 registran un cambio en la tendencia general de participación. 
En el segundo capítulo del monográfico, se ofrece un análisis general de los resultados electorales, así como de la composición final del Parlamento Europeo, previa a la retirada del Reino Unido de las Instituciones europeas. En este sentido, esta sección abunda en el análisis de los procesos electorales europeos, contenido que viene siendo estudiado desde el trabajo compilado por Torcal y Font (2012) y explicado por Fernández-Llebrez y Sánchez (2014) o Tomé da Mata (2015) por citar alguno de los ejemplos más recientes. Estos resultados se ponen en perspectiva al compararlos con otras citas electorales acaecidas en España a lo largo de 2019; y es que, en este país, en un lapso de apenas dos meses se produjeron elecciones de todas las arenas electorales posibles ${ }^{1}$. La consideración que tienen las citas electorales europeas como de «segundo orden» define, en gran medida, las dinámicas, decisiones y participación que se pueden observar en las mismas, si bien es cierto que tampoco se puede olvidar la importancia e influencia del juego político existente en cada uno de los estados miembro.

En este sentido, y en relación con todo lo anteriormente expuesto, el tercer capítulo encuadra y contextualiza los resultados en España de las elecciones europeas, haciendo un análisis longitudinal que no solo comprueba la evolución del voto en los comicios de la UE en lo tocante a España, sino que también analiza la presencia - la denominada oferta partidista - de diferentes formaciones tanto de tipo nacional —Partidos de Ámbito Estatal o PAE - como de ámbito subnacional o regional - Partidos de Ámbito No Estatal o PANE- Los autores destacan la elevada presencia de formaciones no convencionales y de coaliciones entre PANE, en la medida en que el escenario electoral europeo siempre supone una oportunidad para el surgimiento y obtención de representación de formaciones con carácter menos tradicional. Hecho que ya se ha comprobado en otras ocasiones, como fue el caso de la formación Podemos en 2015, debido a que la ciudadanía tiende a optar por otras opciones políticas en estos comicios (García-Rabadán y Trujillo, 2020; Trujillo, 2019) al sentirlas como elecciones de menor importancia que el resto (GarcíaHípola, 2019), perdiendo fuerza el voto estratégico que puede observarse en comicios a otros niveles.

Por su parte, los capítulos cuatro y cinco ponen su foco en la campaña electoral propiamente dicha. Así, para la realización de los análisis que se ofrecen en estos capítulos primero de forma conjunta en toda la UE y posteriormente más focalizado en España-, los autores utilizan la base de datos del Project Platform Europe ${ }^{2}$, financiado por el Parlamento Europeo y que analizó la campaña electoral de las elecciones europeas de mayo de 2019 en los 28 Estados concurrentes en dichos comicios. Se analizaron cerca de 10.000 materiales diferentes entre los que se incluyen anuncios de televisión, cartelería y anuncios

\footnotetext{
${ }^{1}$ Así, en abril se celebraron elecciones nacionales y autonómicas en la Comunidad Valenciana; y en mayo y de forma simultánea, se celebraron elecciones municipales en todo el país, además de europeas, autonómicas en 12 de las Comunidades españolas y a las Diputaciones Forales vascas y cabildos insulares en Baleares y Canarias (Trujillo y García-Hípola, 2020).

${ }^{2}$ Más información sobre el Proyecto mencionado anteriormente puede encontrarse aquí http://www.electionsmonitoringcenter.eu/
} 
en prensa impresa, así como contenido en redes sociales — principalmente Facebookde la práctica totalidad de partidos con opciones de obtener representación (Novelli y Johansson, 2019). Los análisis aquí presentados hablan de una mayor aparición y repetición de contenidos de índole negativo en determinados países como pueden ser Reino Unido o Países Bajos; mientras que en el Sur de Europa fue verdaderamente relevante la actividad en internet, siendo superior a la observada en otras regiones (Mora Rodríguez y Pérez Castaños, 2020). En lo que a España se refiere, la campaña electoral tuvo tintes más nacionales que europeos por parte de todos los partidos analizados, en la medida en que las elecciones europeas se realizaron de forma concurrente con las municipales y varias autonómicas (García-Hípola y Mora Rodríguez, 2020). Así se habla también de la evolución que viven las campañas electorales y los nuevos elementos a tener en cuenta, su traslado a otras esferas como la online y los tempos en que se mueven. Bauman habla de una sociedad líquida, quizás nos encontremos, también, ante campañas electorales líquidas que se van filtrando a otros momentos del día a día político.

Finalmente, en el último de los capítulos se deja de lado el análisis electoral, para poner, en contraposición, el foco de atención sobre los sujetos pasivos de los procesos electorales; esto es, a las y los representantes políticos. De este modo, poniendo el foco en la élite política europea y a través de los datos relativos al perfil y trayectoria que se extrajeron de la base de datos europarlamentarios — provenientes del proyecto «Análisis dinámico de las carreras políticas en el sistema político español: niveles de gobierno estatal y autonómico (Andalucía, Cataluña y Galicia)»³ - el autor realiza un análisis descriptivo de los elementos más interesantes que han influido en la carrera política de aquellas personas que, en un momento u otro, han detentado una posición de representación en el hemiciclo de la UE. Gracias a este análisis, se podría afirmar que la igualdad descriptiva femenina se va alcanzando de forma lenta pero estable en las instituciones europeas, si bien es cierto que por debajo de los niveles que se esperan, teniendo una edad media de en torno a los 50 años y proviniendo en su mayoría de las comunidades autónomas de Madrid, Cataluña, Andalucía o País Vasco (Alarcón González, 2020). Resulta muy relevante en este punto subrayar las diferencias que se observan entre mujeres y hombres, tanto en el perfil demográfico como en el background político de cada sexo.

Con todo, este volumen combina un trabajo tanto de tipo académico-científico como de interés divulgativo, en la medida en que ayuda a acercar el conocimiento de una de las instituciones que la ciudadanía entiende como más lejana (Doz, 2014), así como a desgranar cómo el proceso de elección y el peso relativo de las diferentes formaciones toma valor a través de la campaña electoral. A este tenor, conocer el perfil de las personas que ejercen la representación de la ciudadanía en el PE resulta de capital interés, dado que sirve de referencia para entender el compromiso de las diferentes formaciones políticas con la

\footnotetext{
3 Proyecto de excelencia de la Consejería de Innovación, Ciencia y Empresa de la Junta de Andalucía (P08SEJ-04032) coordinado por Miguel Jerez Mir (Universidad de Granada) y José Real Dato (Universidad de Almería)
} 
propia institución europea. Igualmente, gracias al diálogo que se establece con obras anteriores de la misma temática, supone un abundamiento en el contenido referente a las elecciones europeas. Además, en este trabajo, se pone de manifiesto el avance en la medición de la importancia de la campaña electoral en estos comicios que, como se ha planteado, tienen unas características específicas que podría llegar a convertirlos en un punto de inflexión en la historia de la UE que venimos conociendo.

Es una oportunidad para repasar los elementos que definen nuestra posición frente al Parlamento Europeo y la unión como ente supranacional para desarrollar desde aquí comparaciones a futuro o continuar ahondando en aspectos como los nuevos hitos en las campañas, cambios en los perfiles de los representantes y solución ofrecida a las demandas de la ciudadanía, demandas algunas que van perdiendo su perfil coyuntural.

\section{BIBLIOGRAFÍA}

Alarcón González, F. J. (2020). La élite política europea: perfiles y trayectoria. En Pérez Castaños, S. (Ed.), Elecciones europeas de 2019: campaña electoral voto y liderazgo (143-158). Valencia: Tirant lo Blanch.

Doz, J. (2014). Crisis, desafección ciudadana y refundación de la Unión Europea. Página abierta, vol. 232, 11-13.

Fernández-Llebrez, F. y J. Sánchez (2014). Las elecciones europeas en las comunidades autónomas. Página abierta, n² 233, 12-21

García-Hípola, G. (2019). Elecciones europeas en España (1987-2014): el segundo orden. En García, L. y J. M. Martín (Eds.), El mercado único en la Unión Europea. Balance y perspectivas jurídico-políticas (627-645). Madrid: Dykinson.

García-Hípola, G. y A. Mora Rodríguez (2020). La campaña electoral europea en España. En Pérez Castaños, S. (Ed.), Elecciones europeas de 2019: campaña electoral voto y liderazgo (121-142). Valencia: Tirant lo Blanch.

García-Rabadán, J. y J. M. Trujillo (2020). Las elecciones europeas en España: 32 años de elecciones directas al Parlamento Europeo. En Pérez Castaños, S. (Ed.), Elecciones europeas de 2019: campaña electoral voto y liderazgo (71-96). Valencia: Tirant lo Blanch.

Mora Rodríguez, A. y S. Pérez Castaños (2020). La campaña electoral europea en los 28 estados miembros. En Pérez Castaños, S. (Ed.), Elecciones europeas de 2019: campaña electoral voto y liderazgo (97-119). Valencia: Tirant lo Blanch. 
Novelli, E. y B. Johansson (2019). 2019 European elections campaign. Images, topics, media in the 28 Member States. Bruselas: Parlamento Europeo. http://doi. $\operatorname{org} / 10.2861 / 167439$

Pérez Castaños, S. (2020). Europa en 2019: contexto convulso y cambios sociales. En Pérez Castaños, S. (Ed.), Elecciones europeas de 2019: campaña electoral voto y liderazgo (15-36). Valencia: Tirant lo Blanch.

Tome da Mata, E. (2015). Participación de los ciudadanos de la Unión Europea en las elecciones al Parlamento Europeo y elecciones locales en España. RIPS: Revista de investigaciones políticas y sociológicas, vol. 14, n. ${ }^{\circ} 1,27-62$.

Torcal, M. y J. Font (2012). Elecciones europeas 2009. Madrid: CIS.

Trujillo, J. M. (2019). La competición electoral europea en el contexto español (1979-2014). En García, L. y J. M. Martín (Eds.), El mercado único en la Unión Europea. Balance y perspectivas jurídico-políticas (593-610). Madrid: Dykinson.

Trujillo, J. M. y G. García-Hípola (2020). Entre lo nacional y lo comunitario, de nuevo: situándolos resultados de las elecciones al Parlamento Europeo de 2019. En Pérez Castaños, S. (Ed.), Elecciones europeas de 2019: campaña electoral voto y liderazgo (3769). Valencia: Tirant lo Blanch. 